\title{
SOEP
}

SOEPpapers

SOEPpapers
on Multidisciplinary Panel Data Research

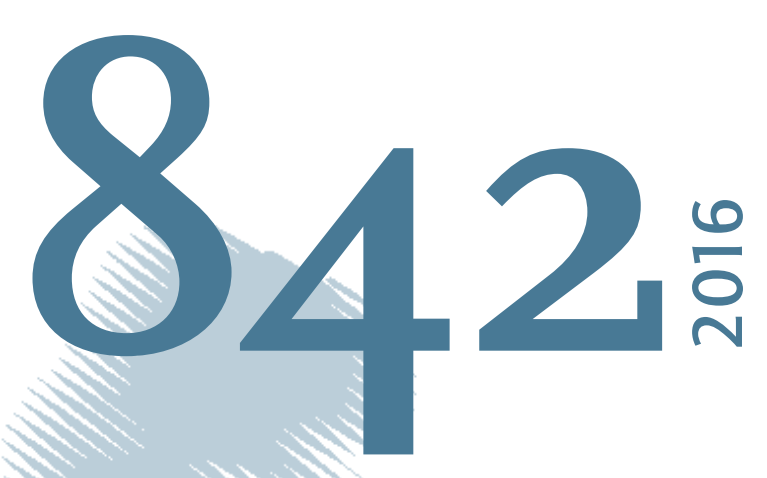

\section{Do Immigrants Suffer More From Job Loss? Unemployment and Subjective Well-Being in Germany}


This series presents research findings based either directly on data from the German SocioEconomic Panel study (SOEP) or using SOEP data as part of an internationally comparable data set (e.g. CNEF, ECHP, LIS, LWS, CHER/PACO). SOEP is a truly multidisciplinary household panel study covering a wide range of social and behavioral sciences: economics, sociology, psychology, survey methodology, econometrics and applied statistics, educational science, political science, public health, behavioral genetics, demography, geography, and sport science.

The decision to publish a submission in SOEPpapers is made by a board of editors chosen by the DIW Berlin to represent the wide range of disciplines covered by SOEP. There is no external referee process and papers are either accepted or rejected without revision. Papers appear in this series as works in progress and may also appear elsewhere. They often represent preliminary studies and are circulated to encourage discussion. Citation of such a paper should account for its provisional character. A revised version may be requested from the author directly.

Any opinions expressed in this series are those of the author(s) and not those of DIW Berlin. Research disseminated by DIW Berlin may include views on public policy issues, but the institute itself takes no institutional policy positions.

The SOEPpapers are available at http://www.diw.de/soeppapers

\section{Editors:}

Jan Goebel (Spatial Economics)

Martin Kroh (Political Science, Survey Methodology)

Carsten Schröder (Public Economics)

Jürgen Schupp (Sociology)

Conchita D'Ambrosio (Public Economics, DIW Research Fellow)

Denis Gerstorf (Psychology, DIW Research Director)

Elke Holst (Gender Studies, DIW Research Director)

Frauke Kreuter (Survey Methodology, DIW Research Fellow)

Frieder R. Lang (Psychology, DIW Research Fellow)

Jörg-Peter Schräpler (Survey Methodology, DIW Research Fellow)

Thomas Siedler (Empirical Economics)

C. Katharina Spieß ( Education and Family Economics)

Gert G. Wagner (Social Sciences)

ISSN: 1864-6689 (online)

German Socio-Economic Panel (SOEP)

DIW Berlin

Mohrenstrasse 58

10117 Berlin, Germany

Contact: Uta Rahmann | soeppapers@diw.de

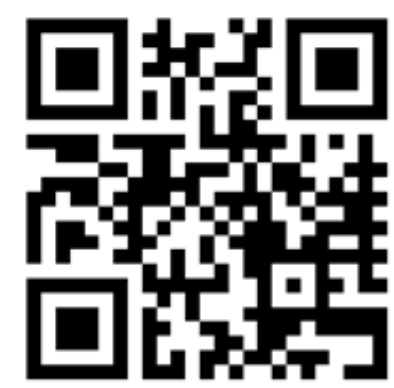




\title{
Do Immigrants Suffer More From Job Loss?
}

\section{Unemployment and Subjective Well-Being in Germany}

Liliya Leopold*, Thomas Leopold**, \& Clemens M. Lechner***

* European University Institute, Italy, liliya.leopold@eui.eu (corresponding author)

** University of Amsterdam, the Netherlands

*** University of Jena, Germany

\begin{abstract}
This study asked whether immigrants suffer more from job loss than German natives do. Compositional, psychosocial, and normative differences between these groups suggest that various factors intensifying the negative impact of unemployment on subjective well-being are either more prevalent, more influential, or distinct among immigrants. Based on longitudinal data from the German Socio-economic Panel Study (1990-2012; $N=36,296$ persons aged 20 to $64 ; N=240,071$ person-years), we used fixed-effects models to trace within-person change in subjective well-being across the transition from employment to unemployment and over several years after job loss. Results showed that immigrants' average declines in subjective well-being exceeded those of natives. Further analyses revealed gender interactions. Declines were smaller and similar among immigrant and native women. Among men, declines were larger and differed between immigrants and natives. Immigrant men showed the largest declines, amounting to one standard deviation of within-person change over time in subjective well-being. We conclude that psychosocial factors render immigrant men most vulnerable to the adverse effects of unemployment.
\end{abstract}

Keywords

Unemployment, immigrants and natives, subjective well-being, panel data, fixed-effects models 


\section{Introduction}

Currently more than 15 million immigrants and their offspring are living in Germany - almost 20 percent of the population (Census 2011). The majority of this group is economically disadvantaged: Immigrants are overrepresented in lower educational tracks, in precarious jobs, among welfare recipients, and especially among the unemployed (Kogan 2004; Riphahn et al. 2013). In most German federal states, more than a third of the unemployed are immigrants (Gehricke et al. 2012).

Although the causes of these problems are well documented (Kogan 2011), little is known about their consequences. In this study, we addressed this gap of knowledge, investigating how unemployment affects the subjective well-being of immigrants and native Germans. Our guiding hypothesis was that immigrants suffer more from unemployment than natives do. We discuss two arguments to support this expectation. First, compositional differences between immigrants and natives suggest that common risk factors exacerbating the negative effects of unemployment are more prevalent among immigrants. Second, psychosocial and normative differences between immigrants and natives suggest that specific risk factors are either distinct or more influential among immigrants.

To test our hypothesis, we analyzed longitudinal data from the German Socio-Economic Panel Study (SOEP). Using fixed-effects panel regression models, we traced changes in subjective well-being among individuals aged 20 to $64(N=36,296$ individuals comprising 240,071 person-years) across an observation period from 1990 until 2012. In this sample, a total of 1,177 immigrants and 4,216 native Germans experienced a transition to unemployment.

\section{Theoretical Background}

Unemployment causes substantial and long-term declines in subjective well-being and other outcomes such as mental and physical health (Wanberg 2012; Paul and Moser 2009). Research has shown that unemployed people typically experience a sharp decline in subjective well-being 
after job loss, followed by a gradual adaptation period (Luhmann et al. 2012). Adaptation to long-term unemployment, however, may be slow and remain incomplete (Clark et al. 2008).

The negative effects of unemployment on subjective well-being are driven by the loss of material resources, the loss of social status, and changes in family roles (Jahoda 1982). These factors, however, do not apply equally across different social groups. Research has shown substantial variation in the consequences of unemployment for subjective well-being, suggesting that certain groups of people are at a higher risk of experiencing these adverse effects (Paul and Moser 2009). Yet, no study has examined differences between immigrants and natives in the consequences of job loss for subjective well-being. This gap of research is notable, given not only the prevalence of unemployment among immigrants, but also the presence of various risk factors that may render this group more vulnerable to the adverse effects of job loss.

\section{Compositional differences}

Immigrants and natives differ with regard to the prevalence of important characteristics that are known to moderate the effects of unemployment on well-being. Among these compositional differences, we consider various factors that may intensify or buffer the effects of unemployment.

Age. On average, unemployed immigrants are younger than unemployed natives (Kogan 2011). Research has indicated that the consequences of unemployment are more severe in early and middle adulthood (Broomhall and Winefield 1990). In this stage of life, individuals carry more family responsibilities as they often provide for dependent children. This increases the importance of stable employment to avoid financial difficulties and social stigma (Brand and Thomas 2014). Among immigrants in Germany, age at parenthood is also lower, and the number of children is higher (Mayer and Riphahn 2000). As a result, immigrants are more likely 
to lose their jobs in a life stage that is particularly vulnerable to the adverse effects of unemployment.

Gender. Men are overrepresented among unemployed immigrants (Kogan 2004). Men, in turn, typically suffer more from unemployment than women (Artazcoz et al. 2004). In contrast to women who may adopt alternative roles of homemakers and mothers, men's identity is strongly linked to the role of a family provider. Job loss not only interferes with this role, but also deprives men of their main stage for gender display (West and Zimmerman 1987), possibly inducing dissonance in their gender identity (Brines 1994). Violation of role expectations and conflicts in personal identity, in turn, are detrimental to subjective well-being (Sharpe and Heppner 1991).

Income. Immigrants are more likely than natives to experience financial hardship after becoming unemployed (Kogan 2004). In Germany, initial unemployment benefits are calculated as a percentage share of prior labor market income. Because immigrants more often work in precarious jobs, they are more likely to cross the poverty line after becoming unemployed. In addition, proving eligibility and applying for unemployment benefits is likely to be more difficult for immigrants, as this requires knowledge of the German language and of the application procedure (Riphahn and Wunder 2013).

Housing. Immigrants have fewer assets to compensate for the loss of income following unemployment. Most notably, they are underrepresented among homeowners (Sinning 2010), rendering them more vulnerable to economic hardship after unemployment. Furthermore, those who do not own their homes may be unable to stay in the same housing unit after job loss. If immigrants are more often forced to downgrade their housing standard — for example in terms of living space - this may intensify the negative effects of unemployment on subjective wellbeing.

Reason for job loss. The literature on worker displacement has shown that the effects of unemployment on subjective well-being depend, to some extent, on the reason for job loss. 
Compared to "voluntary" unemployment (e.g., quitting to look for another job), negative effects are stronger in cases of dismissal or firm closure (Kassenboehmer and Haisken-DeNew 2009). For those who lose their job involuntarily, this transition is associated either with an external shock (in the case of firm closure) or with a negative evaluation of their individual ability or behavior (in the case of dismissal) — both of which are more difficult to cope with than voluntary unemployment. In contrast to the factors previously discussed, it is unclear whether involuntary unemployment as a potential magnifier of unemployment effects on well-being is more prevalent among immigrants. Due to their over-representation in unskilled jobs with low levels of employment protection (Kogan 2004), however, it is conceivable that immigrants more often experience involuntary job loss than do natives.

Religiousness. Religiousness is regarded an important resource in coping with a variety of stressors, including socioeconomic stressors (Bradshaw and Ellison 2010, Lechner et al. 2013). In times of crisis, religious people can draw on social capital residing in religious communities (McClure 2013) as well as personal resources such as efficacy and a sense of meaning in life beyond economic success. Research has shown that the psychological impact of unemployment is smaller, and adaptation faster, among religious people (Lechner and Leopold 2015). In contrast to the factors already discussed, compositional differences in terms of religiousness benefit immigrants, as they attend religious services more frequently than German natives (Jacob and Kalter 2013).

Taken all factors in view, however, the majority of compositional differences favor German natives. This suggests that that immigrants form a more vulnerable group, in which various risk factors that may magnify the negative effects of unemployment on subjective wellbeing are overrepresented. 


\section{Psychosocial and normative differences}

Beyond these compositional differences, research has highlighted psychosocial and normative factors that may aggravate the negative effects of unemployment in immigrants. Most notably, immigrants carry high expectations towards socioeconomic success in their host country (Bartam 2011). High expectations, in turn, intensify the psychological burden in case of failure (Stutzer 2004).

Unlike natives, immigrants have relocated to another country, usually with the hope of building better lives for themselves and their families. This hope implies that success in the host society outweighs the costs of emigration in terms of disrupting social ties and the costs of immigration in terms of adapting to a new culture. These high expectations are far-reaching, as they spread even to the second generation of immigrants (Becker 2010). This is visible, for example, in immigrant parents' aspirations towards educational success of their children. Although immigrant children perform worse in school than native German children, immigrant parents' aspirations vastly exceed those of native parents. A notable example are immigrantnative gaps in the educational aspirations of parents whose children attend the lower secondary track (Hauptschule): 15\% of Ethnic Germans and 45\% of Turkish parents wish that their children later attend university, compared to only 3.6\% of their German counterparts (Becker 2010, p. 137).

Although the definition of what constitutes socioeconomic success in a host society may differ between immigrant groups (Gokdemir and Dumludag 2012), unemployment — especially if long-term - is generally seen as a sign of failure. In view of immigrants' higher expectations towards socioeconomic success, failure to meet these expectations may involve drops in subjective well-being that exceed those of natives.

In the German context, this psychosocial effect should apply particularly to male immigrants. In most immigrant families, men were the initial movers or mainly responsible for moving. The largest immigrant groups in Germany-former "guest workers"-initially 
consisted exclusively of men. If still unmarried, those men went on to marry in Germany; if already married, they reunited with their families after settling down (Münz and Seifert 1999). Ethnic Germans, the second largest group of immigrants, mostly came as male-headed families (Dietz 2000). Hence, men assumed primary responsibility as breadwinners among the largest immigrant groups in Germany, rendering them responsible for improving not only their own lives but also those of their spouses and children.

Moreover, compared with German natives, gender norms are more traditional among immigrants. These differences may put additional pressure on immigrant men. In case of unemployment, immigrant men not only violate stronger gender norms on their role as family providers (Diehl et al. 2009), but they may also experience more dissonance in their gender identities, which are strongly tied to their worker role (Brines 1994; West \& Zimmerman 1987). Based on these considerations, we used gender as a proxy for psychosocial and normative differences in the effects of unemployment on subjective well-being, expecting negative effects to be most pronounced among immigrant men.

\section{Data and Method}

Data

Our empirical analyses were based on data from the German Socio-Economic Panel Study (SOEP). This annual household and person survey started in 1984. For this study's purposes, these data offered two analytical benefits. First, long-run panel data are well-suited to study how the effects of unemployment on subjective well-being unfold over time. Second, the SOEP oversamples immigrants, offering sufficient case numbers to test whether these effects are stronger in this group. 


\section{Sample}

Our analytic sample included observations from 1990 until 2012 (soep-long, version 29, release 2013). Within this window of observation, consistent information was available on all key variables of our analysis. We constrained the sample by a lower age bound of 20 and an upper age bound of 64 , focusing on the typical working-age population. The transition to unemployment was defined as a change from any type of employment to registered unemployment. This definition was based on an item asking respondents whether they were currently registered as unemployed at the Federal Employment Agency. In Germany, registering as unemployed is required in order to receive unemployment benefits and assistance with job search (for details, see Wunder und Riphahn 2013, p. 582), and registered unemployment indicates an ongoing commitment to work for pay. For respondents who experienced more than one transition into unemployment across the observation period, we focused on the first transition recorded in the data. ${ }^{1}$ Before becoming unemployed, $73 \%$ of respondents were employed full time, $15 \%$ were employed part-time, $3.1 \%$ reported other forms of paid employment, and $8.8 \%$ were in vocational training.

For respondents who never became unemployed between 1990 and 2012, we kept all panel observations in which they reported any type of employment. The resulting analytic sample comprised four subsamples: (1) native Germans who experienced the transition to unemployment (event sample of natives, $N=4,216$ individuals and 43,072 person-years); (2) native Germans who did not experience the transition to unemployment (non-event sample of natives, $N=24,830$ individuals and 153,862 person-years); (3) immigrants who experienced the transition to unemployment (event sample of immigrants, $N=1,177$ individuals and 11,265

\footnotetext{
1 Not all transitions out of employment were transitions to unemployment. Other types included transitions to early retirement, parental leave, sickness leave, and quitting work without looking for a new job. Of all transitions out of employment observed in our sample, $53.5 \%$ were transitions to unemployment $(61.2 \%$ among immigrants, $51.2 \%$ among natives).
} 
person-years); and (4) immigrants who did not experience the transition to unemployment (nonevent sample of immigrants, $N=6,073$ individuals and 31,872 person-years).

\section{Measure of subjective well-being}

Since 1984, the SOEP questionnaire includes the following question: "How satisfied are you with your life, all things considered?" This question measures global life satisfaction, the cognitive-evaluative dimension of subjective well-being. Respondents answer on an 11-point scale ranging from zero ("completely dissatisfied") to ten ("completely satisfied"). ${ }^{2}$ Methodological research has shown that this single-item measure is sensitive, valid, and reliable (Diener et al. 2013). It is widely used in studies of life events and subjective well-being.

\section{Measure of unemployment}

We used a set of time dummies to capture how the effects of unemployment on subjective wellbeing unfold over time. These dummy variables indicated whether a respondent (1) had experienced the transition from any form of employment to registered unemployment between the previous and the current wave (0 to 1 year in unemployment); (2) remained unemployed at the subsequent wave ( 1 to 2 years of continued unemployment); and (3) remained unemployed at the next wave and/or throughout the following waves $(>2$ years of continued unemployment $){ }^{3}$ We assessed the effects of these indicators relative to all observations in employment.

\footnotetext{
${ }^{2}$ The distribution of the single-item measure of subjective well-being used in the SOEP (and many other largescale studies) is not perfectly normal but left-skewed. However, the deviation from normality is relatively minor, with skewness amounting to -0.9. This amount of non-normality is unlikely to lead to estimation problems, given the robustness of OLS at large sample sizes. In keeping with a large number of pertinent studies in the field, we therefore analyzed the untransformed variable.

${ }^{3}$ Our yearly data did not allow us to identify the exact timing of job loss or whether longer periods of unemployment were interrupted by shorter employment spells.
} 


\section{Immigrant status}

The focal moderator variable of this study, immigrant status, distinguished between native Germans and immigrants. The latter group included first-generation and second-generation immigrants as well as ethnic Germans who immigrated to Germany from countries of the former Soviet Union or other countries of Eastern Europe. Of the 1,177 immigrants included in the event sample of immigrants, the majority were former guest workers from Turkey $(20.6 \%)$ and other recruitment countries $(27.9 \%)$. Smaller groups were constituted by ethnic Germans (13.6\%), other immigrants from the former Soviet Union (2.8\%) or Eastern Europe (4.8\%), Western European countries $(2.0 \%)$, and other countries of origin $(5.3 \%) ; 22.1 \%$ were second-generation immigrants. In the non-event sample, the proportion of immigrants from Turkey $(12.0 \%)$ and other recruitment countries (18.2\%) was lower, whereas the proportion of immigrants from Western Europe (3.5\%), ethnic Germans (16.5\%), and second-generation immigrants $(28.6 \%)$ was higher.

\section{Measures for compositional differences}

As noted, compositional differences between natives and immigrants may account for potential variation in the effects of unemployment on subjective well-being. To assess this possibility, we included the following covariates.

Age. If immigrants are more likely to experience unemployment in the more vulnerable stages of younger and middle adulthood, this might induce stronger declines in subjective wellbeing. To account for this, we included linear and squared terms of age at the transition to unemployment. This specification captured curvilinear age effects. Because age at the transition to unemployment was time-constant, we interacted these age controls with the dummies for years in unemployment in our models.

Gender. If men are overrepresented among immigrants who become unemployed, these gender differences - rather than immigrant status - may account for differential effects on 
subjective well-being. To test this possibility, we interacted the dummies for years in unemployment with an indicator variable for male gender.

Income. If unemployment of immigrants is more frequently associated with difficulties to make ends meet, economic strain may cause differential effects on subjective well-being. To account for this, we included a time-varying measure for annual post-government household income per capita. This variable is calculated by the SOEP group as the sum of total family income from labor earnings, asset flows, retirement income, private transfers, public transfers, and social security pensions minus family taxes. Private transfers include alimony and child support payments. Public transfers include housing allowances, child benefits, subsistence assistance, and maternity benefits (Grabka 2013). We equivalised this income measure by an elasticity parameter of 0.5 , similar to the scales used by the OECD (Broeckel and Andress 2015). Because a linear income variable cannot capture the effects of crossing a critical lower threshold, we recoded this variable into four categories: more than 20,000 Euros (reference category); 15,000-20,000 Euros; 10,000 to 15,000 Euros, and less than 10,000 Euros (the bottom decile of the distribution).

Receipt of unemployment benefits. In addition to income, we included information about whether respondents who became unemployed received benefits in the year in which the transition was observed (i.e., the first year in unemployment). Unemployed workers who receive these benefits are entitled to living allowance, help in finding work, and training. Our indicator comprised all types of benefits, including Arbeitslosengeld I (approximately two third of previous net salary paid for a limited period to workers who have contributed at least during 12 months before job loss) and Arbeitslosengeld II (an open-ended welfare programme for workers who are not or no longer eligible to Arbeitslosengeld I). To measure whether the effects of receiving unemployment benefits changed over time, interaction this indicator with the dummies for years in unemployment. 
Housing. We used two measures to account for compositional differences in housing. First, we included a time-constant binary indicator for homeownership in the year before becoming unemployed. Like all other time-constant variables, this measure entered the models in the form of interactions with the dummies for years in unemployment. Second, to capture potential effects of downgrading the housing standard, we included time-varying linear and quadratic terms for the size of the living unit, measured in square meters of living space per person.

Reasons for unemployment. In cases of unemployment, the SOEP questionnaire includes items about the reasons for job loss. To assess whether reasons for unemployment differed between immigrants and natives and whether such differences mattered for the effect of unemployment on subjective well-being, we used two indicator variables for dismissal and firm closure. The reference category comprised "voluntary" forms of unemployment, such as wanting to look for another job, personal reasons, time-limited work contract, quitting on one's own, giving up working, and other reasons.

Religiousness. We measured religiousness by the frequency of religious attendance. Our measure compared weekly, monthly, and less frequent attendance to a reference category of individuals who never attended religious services. Because information on religious attendance was only available biannually, we created a time-constant variable measured either at the last observation before unemployment or, if not available, at the second-last observation before unemployment. Like the other time-constant factors, we interacted this variable with the dummies for years in unemployment in order to test for potential buffering effects of religiousness. 


\section{Measures for psychosocial and normative differences}

As outlined in the background, psychological and normative factors exacerbating the negative effects of unemployment on well-being may be either distinct or more influential among immigrants.

Psychosocial factors. The SOEP offers no direct measures for psychosocial differences between immigrants and natives that may moderate the impact of unemployment on subjective well-being. Yet, our theoretical considerations suggested an interaction between immigrant status and gender as a proxy for such psychosocial differences. Specifically, we expected the most severe psychosocial impact of unemployment among immigrant men. To assess this, we used an interaction term between immigrant status and male gender. Because this term was time-constant, we interacted it with the dummies for years in unemployment in the fixed-effects models.

Normative factors. If immigrant men suffer more from unemployment than their German counterparts, this might not necessarily reflect a violation of their higher expectations towards socioeconomic success (i.e., psychosocial differences) but also a violation of more traditional gender roles (i.e., normative differences). To disentangle normative from psychosocial effects, we used information about a key behavioral manifestation of gender roles: the performance of household labor, measured by an item asking respondents to indicate the number of hours they spent on routine housework (washing, cooking, cleaning) on a typical weekday. As a measure for traditional gender roles among men, we defined a binary indicator that equaled one if a respondent reported spending zero hours on routine housework.

\section{Control variables}

Given the time dependency of unemployment effects, it was essential to control for the lifecycle profile (i.e., age-related changes) of subjective well-being. In this regard, it is important to note that our interest was in differences between immigrant and natives in the effects of 
unemployment on well-being across several years after job loss. In testing for heterogeneous effects of unemployment over time, differences in the life-cycle profiles of well-being between immigrants and natives would constitute a potential source of bias. To account for this, we created linear and squared terms of age to capture curvilinear age effects on well-being (Blanchflower and Oswald 2008) and added interactions between these age terms and immigrant status. This nets out potential differences between immigrants' and natives' lifecycle profiles of subjective well-being. ${ }^{4}$

Furthermore, we accounted for variation in subjective well-being over the business cycle. Immigrants in Germany are more likely to become unemployed during economic downturns than natives (Dustmann et al. 2010, Kogan, 2004), possibly creating compositional differences between job losers over the business cycle. Recessions, in turn, are associated with reductions in average levels of subjective well-being (Burgard et al. 2013), suggesting that differences between immigrants and natives might emerge, at least to some extent, from the economic cyclicality of well-being. To account for periodic changes in well-being associated with economic upswings and downturns, we used a time-varying measure for year-to-year changes in economic growth (in percent of the GDP) across our observation window. These data were obtained from the German Federal Statistical Office. Finally, we used a set of timevarying dummies to capture the effects of changes in marital status. These variables indicated whether an individual was single, divorced, widowed, or married (reference category).

\section{- Table $1-$}

Table 1 shows descriptive statistics for all variables included in our multivariate analysis. These descriptive statistics are presented separately for four subsamples (event and non-event samples of natives and immigrants). A comparison between these groups provides information

\footnotetext{
${ }^{4}$ We also included three-way interactions between the age terms, immigrant status, and sample status (event or non-event sample). All parameter estimates for unemployment effects remained almost identical under this specification. Therefore, we used the more parsimonious model including only the two-way interactions between age and immigrant status.
} 
about (a) compositional differences, indicated by the extent to which event samples differed between natives and immigrants; and (b) selectivity, indicated by the extent to which event samples differed from non-event samples.

With regard to compositional differences between the event samples, the data in Table 1 are consistent with our theoretical considerations, although some of the immigrant-native gaps were small. Immigrants were younger when entering unemployment, more often male, more likely to fall below the poverty line, disadvantaged in terms of housing, more likely to become unemployed through dismissal, more likely to become unemployed in periods of lower economic growth, and more religious before unemployment. Moreover, the indicator for gender roles revealed substantial differences between men in the event sample of immigrants (in which almost $40 \%$ performed no housework) and all other subsamples (in which approximately $25 \%$ performed no housework).

With regard to selectivity, a comparison of the event samples to the non-event samples showed that upon first observation (i.e., when still employed), those who went on to become unemployed had a lower average of subjective well-being than those who remained in employment throughout the observation period. This gap was larger among natives than among immigrants, although the latter group reported higher subjective well-being on average. A further pre-event measure, homeownership, indicated that people in the event samples were less often homeowners than those in the control samples.

\section{Item nonresponse and unit nonresponse}

The share of missing data due to item nonresponse was small in our analytic variables. Data on the outcome measure of subjective well-being were missing in $1 \%$ of observations, slightly diminishing the case numbers entering our multivariate models; data on household income were missing in $2.6 \%$ of observations; other analytic variables had negligible shares of less than $1 \%$ of missing data. The only instance of a larger share of missing data $(20.3 \%)$ was the indicator 
for reasons of unemployment. Three quarters of these missing values, however, resulted from variation in the survey instruments, as the respective questions were not included at every wave and for every subsample of the SOEP. These data can be considered to be missing completely at random. The remaining share of refusals was only $5.1 \%$. In view of the low overall prevalence of item nonresponse, we used flag variables for all missing values on our predictor variables.

We conducted additional analyses to assess unit nonresponse in the form of panel attrition from our sample. An important concern was selective attrition among natives and immigrants who became unemployed. If those who suffered most from unemployment dropped out, we would underestimate the negative effect of unemployment on subjective well-being. Furthermore, if selective attrition differed between immigrants and natives, this might bias our conclusions about heterogeneity in the effects of unemployment on well-being. We distinguished between three types of attrition: (1) refusal to stay in the panel, (2) moving abroad, and (3) death. Of all respondents who became unemployed (event samples), $43.3 \%$ (47.5\% of natives, $28.2 \%$ of immigrants) remained in the panel until the most recent wave of 2012; $48.7 \%$ (46.4\% of natives, $57.0 \%$ of immigrants) refused to continue participating in the panel; $2.0 \%$ (1.1\% of natives, $11.8 \%$ of immigrants) moved abroad; and $2.1 \%$ (5.0\% of natives, $3.0 \%$ of immigrants) died.

To assess how these types of dropout-and immigrant-native differences in these types - influenced our results, we interacted the dummies for years in unemployment with all three types of dropout as well as with immigrant status. Although attrition is obviously endogenous to unemployment, these analyses allowed us to assess whether declines in wellbeing were different among immigrants and natives who dropped out for different reasons. Results showed that among natives, people who later refused to stay in the panel had experienced deeper long-term drops in subjective well-being; dropouts due to moving abroad and death were unrelated to preceding declines in subjective well-being. Among immigrants, 
dropout due to refusal was associated with even deeper drops in subjective well-being measured in preceding years than among natives. In contrast to natives, immigrants who moved abroad had also experienced deeper drops in well-being, although these estimates did not reach conventional levels of statistical significance. Taken together, these attrition analyses suggested that (1) negative effects of unemployment on well-being may be underestimated; and (2) that immigrant-native gaps in the effects of unemployment would likely be larger if respondents who dropped out had remained under observation. Therefore, our estimates for immigrantnative differences in the consequences of unemployment should be considered conservative.

\section{Method}

Our guiding hypothesis posited that immigrants suffer more from unemployment than natives do. To test this hypothesis, we used fixed-effects panel regression models (Allison 2009). These models focus solely on intra-individual changes over time, relating temporal variation in subjective well-being only to temporal variation in the explanatory variables. ${ }^{5}$ This is achieved by subtracting within-person means over time from both sides of the equation ("within transformation"). Consequently, only variables that vary over time can enter the model, whereas time-constant variables drop out of the equation. The key advantage of this approach is that it increases confidence in causal inference, as the within transformation renders all time-constant factors inconsequential, even if unobserved.

We modeled subjective well-being of person $i$ at time $t\left(S W B_{i t}\right)$ as a linear function of the dummies for years in unemployment $D_{i t}^{k} \gamma_{k}$ ( $k=0$ to 1 years, 1 to 2 years, $>2$ years in unemployment) and a vector of time-varying covariates $\mathbf{z}_{i t}$ (age and age squared; interactions of age and age squared with immigrant status; marital status, size of housing unit and size of

\footnotetext{
5 Individuals with only one observation are excluded from these models. This restriction did not apply to the event samples, in which every respondent was observed at least twice. In the control samples, approximately $20 \%$ of respondents were observed only once. These respondents did not differ compositionally from the remaining nonevent samples, except for the proportion of married and single people. Respondents observed only once were less likely to be married and more likely to be single.
} 
housing unit squared, household income, and GDP). The effect of immigrant status and the vector of remaining time-constant variables $\mathbf{c}_{i}$ (age at unemployment, age at unemployment squared, homeownership before unemployment, religious attendance before unemployment, men's housework before unemployment, reasons for unemployment, unemployment benefits) were introduced by interactions with the dummies for years in unemployment, giving the model the following equation:

$$
S W B_{i t}=\sum_{k=0 / 1}^{>2} D_{i t}^{k} \gamma_{k}+\sum_{k=0 / 1}^{>2} D_{i t}^{k} \gamma_{k} * \text { Immigrant }_{i}+\sum_{k=0 / 1}^{>2} D_{i t}^{k} \gamma_{k} * \mathbf{c}_{i}+\mathbf{z}_{i t}+\alpha_{i}+\varepsilon_{i t}
$$

In this equation, $\alpha_{i}$ represents the influence of unobserved time-constant variables that drop out of the equation after the within-transformation; $\varepsilon_{i t}$ is the random error for person $i$ at time $t$.

We specified different variants of this model to test our theoretical considerations about (a) differences between immigrants and natives in the effects of unemployment on subjective well-being and (b) compositional, psychosocial, and normative factors that may account for such differential effects. We started with a model that included only the dummies for years in unemployment and the control variables (age, age squared; interactions between age, age squared, and immigrant status; marital status; and GDP); this model estimated average effects of unemployment on subjective well-being irrespective of immigrant status. In Model 2, we added the interactions between time in unemployment and immigrant status; this model estimated differences in the impact of unemployment between immigrants and natives. In Model 3, we added all the compositional variables representing factors that may exacerbate the adverse unemployment effects and that are assumed to be more prevalent among immigrants; this model allowed us to measure the extent to which immigrant-native differences estimated in the preceding model changed after netting out the effects of these compositional differences. In Model 4 (the model corresponding to the equation above), we added the indicators for 
religious attendance, representing the only compositional factor that favored immigrants in terms of buffering the adverse effects of unemployment.

In Model 5, we tested for psychosocial and normative effects by adding the three-way interaction between time in unemployment, immigrant status, and gender. Finally, we disentangled psychosocial and normative differences in Model 6 by adding the interaction between time in unemployment and the indicator variable for traditional gender roles.

\section{Results}

In Table 2, we present the results of the multivariate analysis. Model 1 shows declines in subjective well-being for immigrants and native Germans combined. Conditional on the control variables, declines amounted to approximately 0.8 scale points, or two thirds of a standard deviation, ${ }^{6}$ in the first year after job loss; for those who stayed unemployed, subjective wellbeing remained at this lower level.

\section{- Table $2-$}

Model 2 shows baseline differences between native Germans and immigrants in change of subjective well-being across the transition to unemployment. The negative interactions between the time dummies and immigrant status supported the expectation that drops in subjective well-being are deeper among immigrants. In the first year of unemployment, these differences were small, albeit statistically significant. In this year, immigrants shed an additional tenth of a scale point of subjective well-being. Over time, the gap to unemployed natives increased. In cases of longer-term unemployment, negative effects were almost fifty percent larger among immigrants.

In Model 3, we tested whether compositional risk factors pertaining to immigrants explained these differences. Results on most of these variables were consistent with our

\footnotetext{
6 The standard deviation of within-person change over time in subjective well-being was 1.14 across all observations in our analytic sample $(N=237,619)$.
} 
theoretical expectations. The interaction terms between time in unemployment and age at unemployment indicated a u-shaped relationship in the extent to which subjective well-being declined in unemployment. Furthermore, negative interaction terms for men showed that their declines considerably exceeded those of women. Looking at the economic indicators, results showed that declines in household income were associated with sharp drops in well-being, in particular if income fell into the bottom category indicating financial hardship. The indicators for changes in the quality of housing also showed the expected relationships: Increases in living space were accompanied by increases in subjective well-being, although the curvilinear effect showed that these benefits leveled off at the upper end of the scale. Being a homeowner before unemployment did not buffer negative effects on subjective well-being. Looking at the indicators for receipt of unemployment benefits, results from Model 3 showed that drops in well-being were cushioned among those who received unemployment benefits, although this effect was small in size and pertained only to the first year in unemployment. We also found clear differences with regard to the reason for job loss. Compared to workers who left their jobs "voluntarily," declines in subjective well-being were stronger among those who were fired and particularly in cases of firm closure. Both of these exacerbating effects diminished with longer unemployment duration.

A comparison between Model 2 and Model 3 shows that all compositional factors considered so far explained approximately one third of the immigrant-native gap in the effect of unemployment on subjective well-being. In Model 4, we added the indicators for religious attendance, the only compositional factor favoring immigrants. Results on these measures supported the expectation that religious people suffered less from unemployment. The largest buffer effects were found for the small group of individuals reporting weekly religious attendance, who benefited particularly in cases of long-term unemployment. After inclusion of the interactions with religiousness, the immigrant-native gap reverted back to its initial size. This finding suggests that although immigrants were disadvantaged in most factors intensifying 
the adverse effects of unemployment, the buffer effects of higher religiousness compensated for these differences.

Next, we examined the role of psychosocial and normative effects, adding three-way interactions between the dummies for years in unemployment, immigrant status, and male gender (Model 5). After inclusion of these interaction terms, the main effects of the dummies for years in unemployment pertained to native women; the interactions between the dummies and male gender pertained to native men; the interactions between the time dummies and immigrant status pertained to immigrant women; and the three-way interactions pertained to immigrant men. Results from Model 5 showed that native women and immigrant women did not differ in the effects of unemployment on subjective well-being. Native men suffered more, as their declines exceeded those found for women by approximately 0.2 scale points. Immigrant men, however, emerged as the group that experienced the deepest drops in subjective wellbeing. Compared to their native counterparts, these men shed an additional 0.3 scale points in the first year of unemployment and approximately 0.4 scale points in subsequent years.

In a final step, we added the interactions between time in unemployment and our indicator for traditional gender roles in Model 6 to separate psychosocial from normative effects. Although the point estimate for the first year after job loss indicated that men that were more traditional also suffered more from unemployment, these effects were small and did not explain the gendered pattern found in Model 5.

\section{- Figure $1-$}

To illustrate the differences found in Model 5, Figure 1 presents marginal effects for declines in subjective well-being separately by gender and immigrant status. All other covariates are held at their means. A distinctive pattern of heterogeneous effects emerged at the transition to unemployment, with immigrant men experiencing the steepest declines in subjective well-being: After the first year spent in unemployment, immigrant men's declines in subjective well-being were estimated at approximately 1.1 scale points, or one standard 
deviation. Among those who stayed in unemployment, the differences between immigrant men and the other groups even tended to grow further.

\section{Discussion}

This study asked whether immigrants suffered more from unemployment than German natives did. The answer is yes. Following job loss, immigrants' subjective well-being declined at a steeper rate and adaptation was slower. This immigrant-native gap could not be explained by compositional differences in a variety of factors that are known to either intensify the adverse effects of unemployment or buffer these effects.

In further analyses, we tested whether psychosocial or normative factors accounted for this gap. We had expected that these factors - high expectations towards socioeconomic success in the host society, a high salience of the breadwinner role, and more traditional gender normswould render immigrant men particularly vulnerable to the adverse effects of unemployment. Our results supported these considerations: Whereas no differences emerged between native and immigrant women, we found the deepest drops in subjective well-being among immigrant men. Their decline of more than one scale point, or one standard deviation, ranks among the strongest effects documented in studies on the impact of life events on subjective well-being. Drops of similar magnitude have only been observed in response to widowhood (Clark et al. 2008).

To gain more insight into the social forces driving this exceptional decline, we disentangled psychosocial and normative factors using men's participation in routine housework as a proxy indicator of the strength of traditional gender norms. This indicator showed that immigrant men were far more traditional than native men, suggesting that unemployment violated stronger gender norms concerning their role as providers for the family. These normative differences, however, did not explain why immigrant men suffered more from unemployment. Hence, psychosocial factors emerged from the analysis as the most plausible 
explanation for the immigrant-native gap in the consequences of unemployment on subjective well-being. Although we were unable to measure these factors directly, theoretical considerations suggested that immigrant men carry high expectations towards socioeconomic success in Germany, intensifying psychological deprivation in case of failure. One way to gain more insight into these factors in future research will be to employ measures of vocational aspirations, job centrality, and reasons for migration.

A further potentially important factor that we could not explore in the present study is ethnic discrimination in the labor market. Because there is no evidence to suggest that immigrant men lose their jobs because of discrimination (Kogan 2004), this mechanism is unlikely to account for differences in the initial drops of subjective well-being. However, the stronger long-term effects of unemployment and the absence of adaptation among immigrants could reflect discrimination in the hiring process. Experimental evidence, including a study from Germany (Kaas and Manger 2012), has suggested that immigrant applicants are much less likely to receive invitations to job interviews than are native applicants. Research has also shown that immigrants generally face greater difficulties in finding re-employment than natives do (Kogan 2004). If unemployed immigrants perceive ethnic discrimination in their attempts to re-enter the labor market, this may add to their stress level and exacerbate the adverse effect of unemployment. Given that extant experimental studies did not manipulate the employment status of the applicants, this assertion remains speculative. Future research could gain further insight by investigating discrimination as a possible reason for immigrant-native gaps in unemployment effects.

A limitation of our study is that we did not consider heterogeneity within the group of immigrants in Germany. Some of the explanatory factors highlighted in the present study may apply more strongly to specific subgroups than to others. To name but a few examples, psychosocial factors related to immigration might be more salient among first-generation than among second-generation immigrants. With regard to compositional factors, Turkish 
immigrants may be more likely to benefit from buffer effects of religiosity than ethnic Germans, whereas both groups may suffer more from economic deprivation than Western European immigrants. The limited case numbers available for different immigrant groups, as well as the large number of additional interactions that would be required to explore potential differences between these groups in the multivariate models, did not allow us to consider these possibilities in the present study. Given the large immigrant sample recruited in the 2013 wave of the SOEP, however, these data will soon provide novel opportunities to investigate heterogeneity in the effects of unemployment within different groups of immigrants in Germany.

The relevance of research along these lines is obvious in view of the current streams of refugees seeking asylum in Germany. The German government has recently raised the estimate on refugee arrivals to 800,000 for the year 2015 - the largest influx in the country's post-war history. A major policy aim is to support these new immigrants in entering the German labor market soon after their arrival. Given the completely different context of their immigration, it will be important to explore in future research whether the factors highlighted in this study will also render this group more vulnerable to the consequences of job loss.

Our findings suggest that immigrant men are particularly vulnerable to the adverse consequences of unemployment. In this regard, a large literature has shown that declines in subjective well-being foreshadow declines in mental and physical health. These include increases in depressive symptoms, alcohol and tobacco use, physical limitations, and mortality (Paul and Moser 2009, Helgesson et al. 2014). Importantly, these problems are likely to reverberate through kinship ties (Brand and Thomas 2014), thus affecting not only the unemployed but also their spouses and children. As we have only studied subjective well-being, a precursor to such issues, future research is needed to explore whether, and to what extent, the effects of job loss among immigrant men extend to other outcomes, and to other individuals. 


\section{References}

Allison, P. D. (2009). Fixed effects regression models. Thousand Oaks, CA: Sage.

Artazcoz, L., Benach, J., Borrell, C., \& Cortès, I. (2004). Unemployment and Mental Health: Understanding the Interactions Among Gender, Family Roles, and Social Class. American Journal of Public Health, 94, 82-88.

Bartam, D. (2011). Economic migration and happiness: Comparing immigrants' and natives' happiness gains from income. Social Indicators Research, 103, 57-76.

Becker, B. (2010). Bildungsaspirationen von Migranten: Determinanten und Umsetzung in Bildungsergebnisse [Educational aspirations of migrants: Determinants and conversion into educational outcomes]. Mannheim: Mannheimer Zentrum für Europäische Sozialforschung. Working Paper No. 137.

Blanchflower, D. G., \& Oswald, A. J. (2008). Is well-being U-shaped over the life cycle? Social Science and Medicine, 66, 1733-1749.

Bradshaw, M. \& Ellison, C. G. (2010). Financial hardship and psychological distress: Exploring the buffering effects of religion. Social Science and Medicine, 71, 196-204.

Brand, J. E., \& Thomas, J. S. (2014). Job Displacement among Single Mothers : Effects on Children's Outcomes in Young Adulthood. American Journal of Sociology, 119, 9551001 .

Brines, J. (1994). Economic dependency, gender, and the division of labor at home. American Journal of Sociology, 100, 652-688.

Burgard, S. A., Ailshire, J. A., \& Kalousova, L. (2013). The Great Recession and Health: People, Populations, and Disparities. The Annals of the American Academy of Political and Social Science, 650, 194-213.

Broeckel, M., \& Andress, H.-J. (2015). The economic consequences of divorce in Germany: What has changed since the turn of the millennium? Comparative Population Studies. 
Broomhall, H. S., \& Winefield, A. H. (1990). A Comparison of the Affective Well-being of Young and Middle-Aged Unemployed Men Matched for Length of Unemployment. British Journal of Medical Psychology, 63, 43-52.

Census (2011). Statistische Ämter des Bundes und der Länder. www.zensus2011.de/EN.

Clark, A. E., Diener, E., Georgellis, Y., \& Lucas, R. E. (2008). Lags and Leads in Life Satisfaction: A Test of the Baseline Hypothesis. The Economic Journal, 118, 222-243.

Diehl, C., Koenig, M., \& Ruckdeschel, K. (2009). Religiosity and Gender Equality: Comparing Natives and Muslim Migrants in Germany. Ethnic and Racial Studies, 32, 278-301.

Diener, E., Inglehart, R., \& Tay, L. (2013). Theory and Validity of Life Satisfaction Scales. Social Indicators Research, 112, 497-527.

Dietz, B. (2000). German and Jewish Migration from the Former Soviet Union to Germany: Background, Trends and Implications. Journal of Ethnic and Migration Studies, 26, $635-652$.

Dustmann, C., Glitz, A., \& Vogel, T. (2010). Employment, wages, and the economic cycle: Differences between immigrants and natives. European Economic Review, 54, 1-17.

Gehricke, M., Fritz, J., \& Roß, H. (2012). Methodenbericht Arbeitslose mit Migrationshintergrund [Methods report on unemployed people with migration background]. Nürnberg: Bundesagentur für Arbeit.

Gokdemir, O., \& Dumludag, D. (2011). Life Satisfaction Among Turkish and Moroccan Immigrants in the Netherlands: The Role of Absolute and Relative Income. Social Indicators Research, 106, 407-417.

Grabka, M. M. (2013). SOEP 2012 - Codebook for the \$PEQUIV File 1984-2012. CNEF Variables with extended income information for the SOEP. DIW Berlin: SOEP Survey Paper No. 143.

Helgesson, M., Johansson, B., Nordqvist, T., Lundberg, I., \& Vingård, E. (2013). Unemployment at a Young Age and Later Sickness Absence, Disability Pension and 
Death in Native Swedes and Immigrants. European Journal of Public Health, 23, 606610

Jacob, K., \& Kalter, F. (2013). Intergenerational change in religious salience among immigrant families in four European vountries. International Migration, 51, 38-56.

Jahoda M. (1982). Employment and unemployment: A social-psychological analysis. Cambridge: Cambridge University Press.

Kaas, L. \& Manger, C. (2012). Ethnic Discrimination in Germany's Labour Market: A Field Experiment. German Economic Review, 13, 1-20.

Kassenboehmer, S. C. \& Haisken-DeNew, J. P. (2009). You're fired! The Causal Negative Effect of Unemployment on Life Satisfaction. Economic Journal, 536, 448-462.

Kogan, I. (2004). Last Hired, First Fired? The Unemployment Dynamics of Male Immigrants in Germany. European Sociological Review, 20, 445-461.

Kogan, I. (2011). New immigrants - Old Disadvantage Patterns? Labour Market Integration of Recent Immigrants into Germany. International Migration, 49, 91-117.

Lechner, C. M., \& Leopold, T. (2015). Religious Attendance Buffers the Impact of Unemployment on Life Satisfaction: Longitudinal Evidence from Germany. Journal for the Scientific Study of Religion, 54, 166-174.

Lechner, C. M., Tomasik, M. J., Wasilewski, J., \& Silbereisen, R. K. (2013). Exploring the stress-buffering effects of religiousness in relation to social and economic change: Evidence from Poland. Psychology of Religion and Spirituality, 5, 145-156.

Luhmann, Maike, Wilhelm Hofmann, Michael Eid, and Richard E. Lucas. (2012). Subjective well-being and adaptation to life events: A meta-analysis. Journal of Personality and Social Psychology, 102, 592-615.

Mayer, J., \& Riphahn, R. T. (2000). Fertility Assimilation of Immigrants : Evidence from Count Data Models. Journal of Population Economics, 13, 241-261. 
McClure, J. M. (2013). Sources of social support: Examining congregational involvement, private devotional activities, and congregational context. Journal for the Scientific Study of Religion, 52, 698-712.

Münz R., \& Seifert, W. (1999). Zuwanderung nach Deutschland: Strukturen, Wirkungen, Perspektiven. Frankfurt am Main: Campus.

Paul, K. I., \& Moser, K. (2009). Unemployment Impairs Mental Health: Meta-Analyses. Journal of Vocational Behavior, 74, 264-282.

Riphahn, R. T., Sander, M., \& Wunder, C. (2013). The Welfare Use of Immigrants and Natives in Germany: The Case of Turkish Immigrants. International Journal of Manpower, 34, $70-82$.

Riphahn, R. T. \& Wunder, C. (2013). Patterns of Welfare Dependence Before and After a Reform: Evidence from First Generation Immigrants and Natives in Germany. Review of Income and Wealth, 59, 437-459.

Sharpe, M. J.; \& Heppner, P. P. (1991). Gender Role, Gender-Role Conflict, and Psychological Well-Being in Men. Journal of Counseling Psychology, 38, 323-330.

Sinning, M. (2010). Homeownership and economic performance of immigrants in Germany. Urban Studies, 47, 387-409.

Stutzer, A. (2004). The Role of Income Aspirations in Individual Happiness. Journal of Economic Behavior \& Organization, 54, 89-109.

Wanberg, C. R. (2012). The Individual Experience of Unemployment. Annual Review of Psychology, 63, 369-96.

West, C., \& Zimmerman, D. H. (1987). Doing gender. Gender and Society, 1, 125-151. 


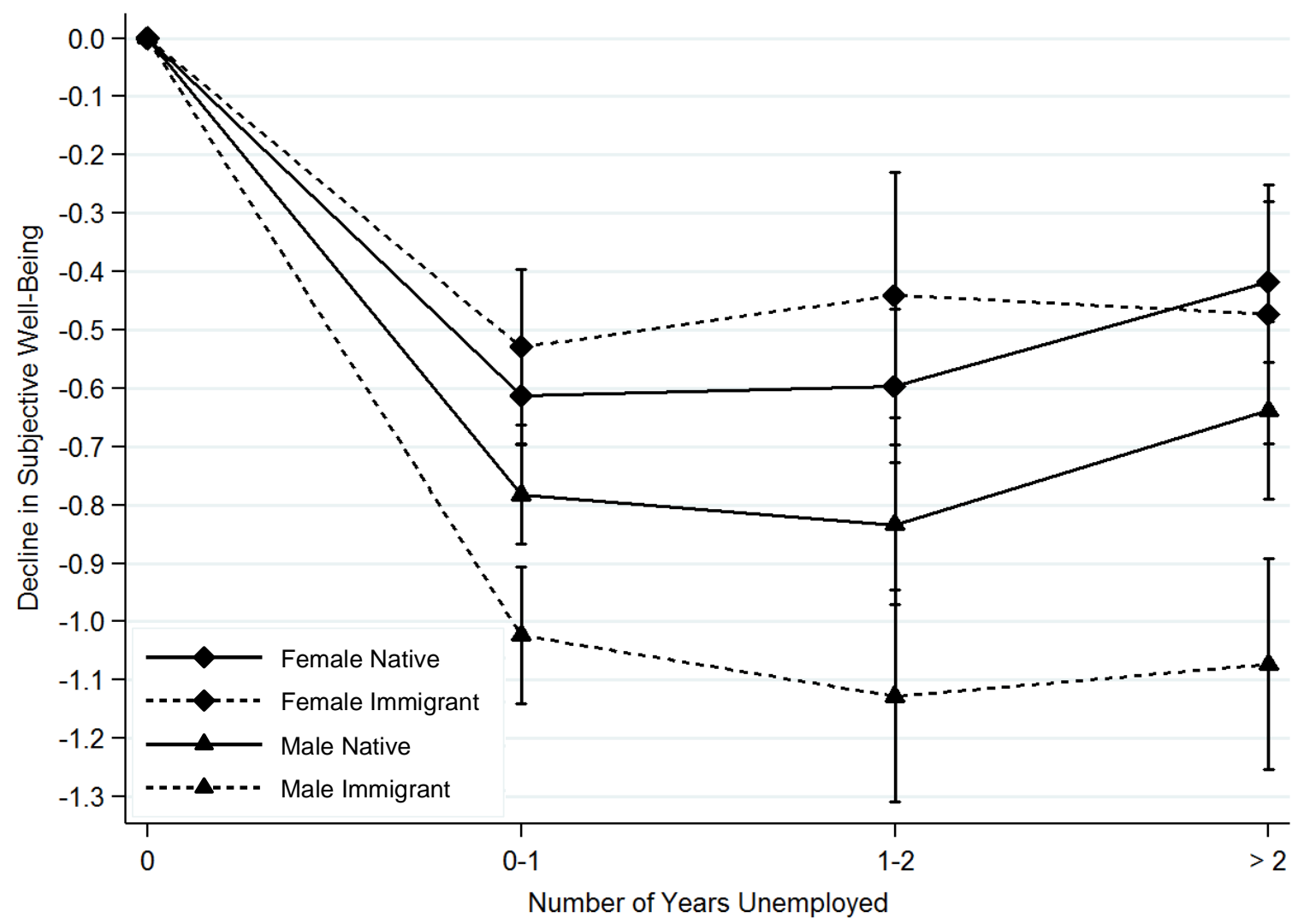

Figure 1. Changes in Subjective Well-Being Across the Transition to Unemployment

Note: SOEP 1990-2012, release 2013. $N=35,331$ individuals, $N=237,619$ observations (person-years). Y-axis shows change in life satisfaction scores. One standard deviation of within-person change in life satisfaction over time is 1.14. Marginal effects of time in unemployment and 95\% confidence intervals are shown. Estimates from Model 5, all covariates fixed at their means. See Table 2 for details on the estimation. 
TABLE 1. DESCRIPTIVE STATISTICS

\begin{tabular}{|c|c|c|c|c|c|c|c|c|c|c|c|c|c|c|c|c|}
\hline & \multicolumn{8}{|c|}{ Natives } & \multicolumn{8}{|c|}{ Immigrants } \\
\hline & \multicolumn{4}{|c|}{ Event sample } & \multicolumn{4}{|c|}{ Non-event sample } & \multicolumn{4}{|c|}{ Event sample } & \multicolumn{4}{|c|}{ Non-event sample } \\
\hline & M & SD & Min & Max & M & SD & Min & $\operatorname{Max}$ & M & SD & Min & $\operatorname{Max}$ & M & SD & Min & $\operatorname{Max}$ \\
\hline Male & .52 & & 0 & 1 & .52 & & 0 & 1 & .60 & & 0 & 1 & .53 & & 0 & 1 \\
\hline Subjective well-being ${ }^{\dagger,}$ a & 6.85 & 1.83 & 0 & 10 & 7.37 & 1.64 & 0 & 10 & 7.24 & 1.70 & 0 & 10 & 7.42 & 1.70 & 0 & 10 \\
\hline Age $^{*}$ & 40.80 & 12.81 & 21 & 64 & 41.46 & 11.15 & 20 & 64 & 40.55 & 11.84 & 20 & 64 & 39.05 & 11.58 & 20 & 64 \\
\hline \multicolumn{17}{|l|}{ Household income ${ }^{*}$, b } \\
\hline$>20,000$ Euros & .33 & & 0 & 1 & .57 & & 0 & 1 & .25 & & 0 & 1 & .39 & & 0 & 1 \\
\hline $15,000-20,000$ Euros & .25 & & 0 & 1 & .22 & & 0 & 1 & .27 & & 0 & 1 & .28 & & 0 & 1 \\
\hline $10,000-15,000$ Euros & .25 & & 0 & 1 & .14 & & 0 & 1 & .33 & & 0 & 1 & .25 & & 0 & 1 \\
\hline$<10,000$ Euros & .11 & & 0 & 1 & .04 & & 0 & 1 & .15 & & 0 & 1 & .08 & & 0 & 1 \\
\hline Missing & .06 & & 0 & 1 & .02 & & 0 & 1 & .01 & & 0 & 1 & .00 & & 0 & 1 \\
\hline Number of persons in household* & 2.84 & 1.18 & 1 & 11 & 2.90 & 1.21 & 1 & 14 & 3.34 & 1.57 & 1 & 15 & 3.30 & 1.50 & 1 & 15 \\
\hline \multicolumn{17}{|l|}{ Marital status* } \\
\hline Married & .62 & & 0 & 1 & .64 & & 0 & 1 & .69 & & 0 & 1 & .69 & & 0 & 1 \\
\hline Single & .24 & & 0 & 1 & .26 & & 0 & 1 & .21 & & 0 & 1 & .23 & & 0 & 1 \\
\hline Divorced & .12 & & 0 & 1 & .09 & & 0 & 1 & .08 & & 0 & 1 & .07 & & 0 & 1 \\
\hline Widowed & .02 & & 0 & 1 & .01 & & 0 & 1 & .02 & & 0 & 1 & .01 & & 0 & 1 \\
\hline \multicolumn{17}{|l|}{ Religious attendance ${ }^{\S}$} \\
\hline Never & .68 & & 0 & 1 & .53 & & 0 & 1 & .49 & & 0 & 1 & .46 & & 0 & 1 \\
\hline Less than monthly & .22 & & 0 & 1 & .30 & & 0 & 1 & .26 & & 0 & 1 & .24 & & 0 & 1 \\
\hline Monthly & .05 & & 0 & 1 & .08 & & 0 & 1 & .11 & & 0 & 1 & .12 & & 0 & 1 \\
\hline Weekly & .04 & & 0 & 1 & .06 & & 0 & 1 & .13 & & 0 & 1 & .14 & & 0 & 1 \\
\hline \multicolumn{17}{|l|}{ Housing } \\
\hline Home owner ${ }^{\S}$ & .39 & & 0 & 1 & .56 & & 0 & 1 & .18 & & 0 & 1 & .36 & & 0 & 1 \\
\hline Living space per person $\left(\mathrm{m}^{2}\right)$ & 37.04 & 19.64 & 2.75 & 320 & 42.37 & 22.23 & 2 & 377 & 29.02 & 16.57 & 3.60 & 220 & 32.86 & 19.46 & 1.67 & 400 \\
\hline Gender roles: No housework ${ }^{\S, c}$ & .25 & & 0 & 1 & .23 & & 0 & 1 & .38 & & 0 & 1 & .26 & & 0 & 1 \\
\hline \multicolumn{17}{|l|}{ Context of unemployment ${ }^{\infty}$} \\
\hline Age at unemployment & 40.05 & 13.05 & 21 & 64 & & & & & 39.50 & 13.31 & 21 & 64 & & & & \\
\hline Year of unemployment & 2000 & 6.25 & 1991 & 2012 & & & & & 1999 & 5.77 & 1991 & 2012 & & & & \\
\hline Involuntary: Fired ${ }^{\mathrm{d}}$ & .39 & & 0 & 1 & & & & & .44 & & 0 & 1 & & & & \\
\hline Involuntary: Firm closed ${ }^{\mathrm{e}}$ & .17 & & 0 & 1 & & & & & .15 & & 0 & 1 & & & & \\
\hline Voluntary ${ }^{f}$ & .37 & & 0 & 1 & & & & & .35 & & 0 & 1 & & & & \\
\hline Benefits: $\mathrm{Yes}^{\mathrm{g}}$ & .59 & & 0 & 1 & & & & & .59 & & 0 & 1 & & & & \\
\hline Economic growth ${ }^{\mathrm{h}}$ & 1.60 & 2.05 & -5.6 & 5.2 & & & & & 1.52 & 1.92 & -5.6 & 5.2 & & & & \\
\hline Number of individuals & \multicolumn{4}{|c|}{4,216} & \multicolumn{4}{|c|}{24,830} & \multicolumn{4}{|c|}{1,177} & \multicolumn{4}{|c|}{6,073} \\
\hline Number of observations & \multicolumn{4}{|c|}{43,072} & \multicolumn{4}{|c|}{153,862} & \multicolumn{4}{|c|}{11,265} & \multicolumn{4}{|c|}{31,872} \\
\hline
\end{tabular}

Note: SOEP 1990-2012, release 2013. ${ }^{\dagger}$ Measured at first observation. $*$ Measured across all observations. ${ }^{\S}$ For the event samples, measured in the year before unemployment $($ mean age $=39$ ); for the nonevent samples, measured at age $39 .{ }^{\infty}$ Measured in the first year of registered unemployment. ${ }^{a}$ Measured on an 11-point scale of life satisfaction. ${ }^{\mathrm{b}}$ Annual post government household income calculated by the SOEP group as the sum of total family income from labor earnings, asset flows, retirement income, private transfers, public transfers, and social security pensions, minus family taxes; equivalized by elasticity parameter $0.5 .{ }^{\mathrm{c}}$ Respondent performs 0 hours of routine housework (washing, cooking, cleaning) on a typical weekday. ${ }^{\mathrm{d}}$ Fired by employer. ${ }^{\mathrm{e}}$ Firm closed within past 12 months. ${ }^{\mathrm{i}}$ Quit for one of the following reasons: Wanting to look for another job, personal reasons, time-limited work contract, quit on one's own, giving up working, other reasons. ${ }^{\mathrm{g}}$ Respondent receives unemployment benefits (all types considered).

${ }^{\mathrm{h}}$ Average economic growth (year to year change in GDP). 
Table 2. Fixed-Effects Models for Change in Subjective Well-Being

\begin{tabular}{|c|c|c|c|c|c|c|c|c|c|c|c|c|}
\hline \multirow[b]{2}{*}{ Years unemployed (ref. 0) } & \multicolumn{2}{|c|}{ Model 1} & \multicolumn{2}{|c|}{ Model 2} & \multicolumn{2}{|c|}{ Model 3} & \multicolumn{2}{|c|}{ Model 4} & \multicolumn{2}{|c|}{ Model 5} & \multicolumn{2}{|c|}{ Model 6} \\
\hline & & & & & & & & & & & & \\
\hline $0-1$ & $-0.79 * * *$ & $(0.02)$ & $-0.77 * * *$ & $(0.02)$ & $-0.59 * * *$ & $(0.05)$ & $-0.62 * * *$ & $(0.05)$ & $-0.66 * * *$ & $(0.05)$ & $-0.66 * * *$ & $(0.05)$ \\
\hline $1-2$ & $-0.81 * * *$ & $(0.03)$ & $-0.78 * * *$ & $(0.03)$ & $-0.54 * * *$ & $(0.08)$ & $-0.56 * * *$ & $(0.08)$ & $-0.61 * * *$ & $(0.08)$ & $-0.61 * * *$ & $(0.08)$ \\
\hline$>2$ & $-0.68 * * *$ & $(0.03)$ & $-0.61 * * *$ & $(0.04)$ & $-0.36 * * *$ & $(0.08)$ & $-0.42 * * *$ & $(0.08)$ & $-0.47 * * *$ & $(0.08)$ & $-0.47 * * *$ & $(0.08)$ \\
\hline \multicolumn{13}{|l|}{ Years unemployed $\mathrm{x}$ Immigrant } \\
\hline 0-1 x Immigrant & & & $-0.09 *$ & $(0.04)$ & -0.06 & $(0.05)$ & $-0.11 *$ & $(0.05)$ & 0.08 & $(0.07)$ & 0.08 & $(0.07)$ \\
\hline $1-2 \times$ Immigrant & & & $-0.12+$ & $(0.07)$ & -0.05 & $(0.07)$ & -0.11 & $(0.07)$ & 0.16 & $(0.11)$ & 0.16 & $(0.11)$ \\
\hline$>2 \mathrm{x}$ Immigrant & & & $-0.26 * * *$ & $(0.07)$ & $-0.18^{*}$ & $(0.07)$ & $-0.29 * * *$ & $(0.08)$ & -0.06 & $(0.12)$ & -0.05 & $(0.12)$ \\
\hline \multicolumn{13}{|l|}{ Years unemployed x Male } \\
\hline $0-1 \times$ Male & & & & & $-0.25 * * *$ & $(0.04)$ & $-0.24 * * *$ & $(0.04)$ & $-0.17 * * *$ & $(0.04)$ & $-0.13 * *$ & $(0.05)$ \\
\hline $1-2 \times$ Male & & & & & $-0.35 * * *$ & $(0.06)$ & $-0.34 * * *$ & $(0.06)$ & $-0.24 * * *$ & $(0.07)$ & $-0.26 * * *$ & $(0.08)$ \\
\hline$>2 \times$ Male & & & & & $-0.34 * * *$ & $(0.06)$ & $-0.31 * * *$ & $(0.06)$ & $-0.22 * *$ & $(0.07)$ & $-0.18 *$ & $(0.08)$ \\
\hline \multicolumn{13}{|l|}{ Years unemployed $\mathrm{x}$ Immigrant $\mathrm{x}$ Male } \\
\hline 0-1 x Immigrant $\mathrm{x}$ Male & & & & & & & & & $-0.32 * * *$ & $(0.09)$ & $-0.31 * * *$ & $(0.09)$ \\
\hline 1-2 x Immigrant $\mathrm{x}$ Male & & & & & & & & & $-0.45 * *$ & $(0.14)$ & $-0.46 * *$ & $(0.14)$ \\
\hline$>2 \times$ Immigrant $x$ Male & & & & & & & & & $-0.38 * *$ & $(0.15)$ & $-0.37 *$ & $(0.15)$ \\
\hline \multicolumn{13}{|c|}{ Years unemployed x Housework (ref. $>0$ hours) } \\
\hline $0-1$ x No housework & & & & & & & & & & & $-0.09+$ & $(0.05)$ \\
\hline $1-2 \times$ No housework & & & & & & & & & & & 0.05 & $(0.08)$ \\
\hline$>2 \times$ No housework & & & & & & & & & & & -0.08 & $(0.09)$ \\
\hline \multicolumn{13}{|l|}{ Years unemployed x Age at unemployment } \\
\hline $0-1 \times$ Age at unemployment & & & & & $-0.07 * * *$ & $(0.01)$ & $-0.07 * * *$ & $(0.01)$ & $-0.07 * * *$ & $(0.01)$ & $-0.07 * * *$ & $(0.01)$ \\
\hline 1-2 x Age at unemployment & & & & & $-0.11 * * *$ & $(0.02)$ & $-0.11 * * *$ & $(0.02)$ & $-0.11 * * *$ & $(0.02)$ & $-0.11 * * *$ & $(0.02)$ \\
\hline$>2 \times$ Age at unemployment & & & & & $-0.12 * * *$ & $(0.02)$ & $-0.12 * * *$ & $(0.02)$ & $-0.12 * * *$ & $(0.02)$ & $-0.13 * * *$ & $(0.02)$ \\
\hline 0-1 x Age at unemployment squared & & & & & $0.00 * * *$ & $(0.00)$ & $0.00 * * *$ & $(0.00)$ & $0.00 * * *$ & $(0.00)$ & $0.00 * * *$ & $(0.00)$ \\
\hline 1-2 x Age at unemployment squared & & & & & $0.00 * * *$ & $(0.00)$ & $0.00 * * *$ & $(0.00)$ & $0.00 * * *$ & $(0.00)$ & $0.00 * * *$ & $(0.00)$ \\
\hline$>2 \times$ Age at unemploymen squared & & & & & $0.00 * * *$ & $(0.00)$ & $0.00 * * *$ & $(0.00)$ & $0.00 * * *$ & $(0.00)$ & $0.00 * * *$ & $(0.00)$ \\
\hline \multicolumn{13}{|l|}{ Household income (ref. > 20,000 Euros) } \\
\hline $15,000-20,000$ & & & & & $-0.09 * * *$ & $(0.01)$ & $-0.09 * * *$ & $(0.01)$ & $-0.09 * * *$ & $(0.01)$ & $-0.09 * * *$ & $(0.01)$ \\
\hline $10,000-15,000$ & & & & & $-0.18 * * *$ & $(0.01)$ & $-0.18 * * *$ & $(0.01)$ & $-0.18 * * *$ & $(0.01)$ & $-0.18 * * *$ & $(0.01)$ \\
\hline$<10,000$ & & & & & $-0.35 * * *$ & $(0.02)$ & $-0.35 * * *$ & $(0.02)$ & $-0.35 * * *$ & $(0.02)$ & $-0.35 * * *$ & $(0.02)$ \\
\hline \multicolumn{13}{|l|}{ Living space per person (in $20 \mathrm{~m}^{2}$ ) } \\
\hline Living space & & & & & $0.07 * * *$ & $(0.01)$ & $0.07 * * *$ & $(0.01)$ & $0.07 * * *$ & $(0.01)$ & $0.07 * * *$ & $(0.01)$ \\
\hline Living space squared & & & & & $-0.01 * * *$ & $(0.00)$ & $-0.01 * * *$ & $(0.00)$ & $-0.01 * * *$ & $(0.00)$ & $-0.01 * * *$ & $(0.00)$ \\
\hline \multicolumn{13}{|l|}{ Years unemployed x Homeowner (ref. no) } \\
\hline 0-1 x Homeowner & & & & & 0.05 & $(0.04)$ & 0.02 & $(0.04)$ & 0.02 & $(0.04)$ & 0.02 & $(0.04)$ \\
\hline 1-2 x Homeowner & & & & & 0.06 & $(0.06)$ & 0.04 & $(0.06)$ & 0.04 & $(0.06)$ & 0.03 & $(0.06)$ \\
\hline$>2 \times$ Homeowner & & & & & -0.02 & $(0.07)$ & -0.05 & $(0.07)$ & -0.04 & $(0.07)$ & -0.03 & $(0.07)$ \\
\hline
\end{tabular}




\begin{tabular}{|c|c|c|c|c|c|c|c|c|c|c|c|c|}
\hline \multicolumn{13}{|l|}{ Years unemployed x Benefits (ref. no) } \\
\hline $0-1 \times$ Benefits & & & & & $0.13 * * *$ & $(0.04)$ & $0.13 * *$ & $(0.04)$ & $0.12 * *$ & $(0.04)$ & $0.12 * *$ & $(0.04)$ \\
\hline $1-2 \times$ Benefits & & & & & 0.08 & $(0.06)$ & 0.08 & $(0.06)$ & 0.07 & $(0.06)$ & 0.07 & $(0.06)$ \\
\hline$>2 \times$ Benefits & & & & & 0.01 & $(0.06)$ & 0.01 & $(0.06)$ & 0.00 & $(0.06)$ & 0.00 & $(0.06)$ \\
\hline \multicolumn{13}{|c|}{ Years unemployed x Reason (ref. voluntary) } \\
\hline $0-1 \times$ Fired & & & & & $-0.25 * * *$ & $(0.05)$ & $-0.25 * * *$ & $(0.05)$ & $-0.24 * * *$ & $(0.05)$ & $-0.24 * * *$ & $(0.05)$ \\
\hline $1-2 \times$ Fired & & & & & $-0.21 * *$ & $(0.07)$ & $-0.21 * *$ & $(0.07)$ & $-0.20 * *$ & $(0.07)$ & $-0.20 * *$ & $(0.07)$ \\
\hline$>2 \times$ Fired & & & & & $-0.16^{*}$ & $(0.08)$ & $-0.14+$ & $(0.08)$ & -0.13 & $(0.08)$ & -0.12 & $(0.08)$ \\
\hline 0-1 x Firm closed & & & & & $-0.45 * * *$ & $(0.06)$ & $-0.45 * * *$ & $(0.06)$ & $-0.45 * * *$ & $(0.06)$ & $-0.45 * * *$ & $(0.06)$ \\
\hline 1-2 x Firm closed & & & & & $-0.42 * * *$ & $(0.09)$ & $-0.42 * * *$ & $(0.09)$ & $-0.40 * * *$ & $(0.09)$ & $-0.40 * * *$ & $(0.09)$ \\
\hline$>2 \times$ Firm closed & & & & & $-0.24 *$ & $(0.10)$ & $-0.23 *$ & $(0.10)$ & $-0.21 *$ & $(0.10)$ & $-0.22 *$ & $(0.10)$ \\
\hline \multicolumn{13}{|l|}{ Years unemployed x Church (ref. never) } \\
\hline $0-1$ x Less than monthly & & & & & & & $0.13 * *$ & $(0.05)$ & $0.13 * *$ & $(0.05)$ & $0.14 * *$ & $(0.05)$ \\
\hline $1-2 \mathrm{x}$ Less than monthly & & & & & & & 0.01 & $(0.07)$ & 0.01 & $(0.07)$ & 0.01 & $(0.07)$ \\
\hline$>2 \mathrm{x}$ Less than monthly & & & & & & & 0.13 & $(0.08)$ & 0.12 & $(0.08)$ & 0.12 & $(0.08)$ \\
\hline $0-1$ x Monthly & & & & & & & $0.20 *$ & $(0.08)$ & $0.21 * *$ & $(0.08)$ & $0.22 * *$ & $(0.08)$ \\
\hline 1-2 x Monthly & & & & & & & 0.17 & $(0.13)$ & 0.17 & $(0.13)$ & 0.17 & $(0.13)$ \\
\hline$>2 \mathrm{x}$ Monthly & & & & & & & 0.12 & $(0.13)$ & 0.13 & $(0.13)$ & 0.13 & $(0.13)$ \\
\hline 0-1 x Weekly & & & & & & & $0.23 * *$ & $(0.08)$ & $0.24 * *$ & $(0.08)$ & $0.24 * *$ & $(0.08)$ \\
\hline 1-2 x Weekly & & & & & & & $0.36^{* *}$ & $(0.12)$ & $0.36 * *$ & $(0.12)$ & $0.36^{* *}$ & $(0.12)$ \\
\hline$>2 x$ Weekly & & & & & & & $0.62 * * *$ & $(0.12)$ & $0.62 * * *$ & $(0.12)$ & $0.62 * * *$ & $(0.12)$ \\
\hline \multicolumn{13}{|l|}{ Controls } \\
\hline Age (mean-centered) & $-0.03 * * *$ & $(0.00)$ & $-0.03 * * *$ & $(0.00)$ & $-0.04 * * *$ & $(0.00)$ & $-0.04 * * *$ & $(0.00)$ & $-0.04 * * *$ & $(0.00)$ & $-0.04 * * *$ & $(0.00)$ \\
\hline Age $x$ Immigrant & 0.00 & $(0.01)$ & 0.00 & $(0.01)$ & 0.01 & $(0.01)$ & 0.01 & $(0.01)$ & 0.01 & $(0.01)$ & 0.01 & $(0.01)$ \\
\hline Age squared (mean-centered) & $0.00 *$ & $(0.00)$ & $0.00 *$ & $(0.00)$ & 0.00 & $(0.00)$ & 0.00 & $(0.00)$ & 0.00 & $(0.00)$ & 0.00 & $(0.00)$ \\
\hline Age squared $\mathrm{x}$ Immigrant & $-0.00+$ & $(0.00)$ & -0.00 & $(0.00)$ & $-0.00 *$ & $(0.00)$ & $-0.00 *$ & $(0.00)$ & $-0.00 *$ & $(0.00)$ & $-0.00 *$ & $(0.00)$ \\
\hline \multicolumn{13}{|l|}{ Marital status (ref. married) } \\
\hline Single & $-0.12 * * *$ & $(0.02)$ & $-0.12 * * *$ & $(0.02)$ & $-0.14 * * *$ & $(0.02)$ & $-0.14 * * *$ & $(0.02)$ & $-0.14 * * *$ & $(0.02)$ & $-0.14 * * *$ & $(0.02)$ \\
\hline Divorced & $-0.16 * * *$ & $(0.02)$ & $-0.16 * * *$ & $(0.02)$ & $-0.14 * * *$ & $(0.02)$ & $-0.14 * * *$ & $(0.02)$ & $-0.14 * * *$ & $(0.02)$ & $-0.14 * * *$ & $(0.02)$ \\
\hline Widowed & $-0.29 * * *$ & $(0.05)$ & $-0.29 * * *$ & $(0.05)$ & $-0.29 * * *$ & $(0.05)$ & $-0.29 * * *$ & $(0.05)$ & $-0.30 * * *$ & $(0.05)$ & $-0.30 * * *$ & $(0.05)$ \\
\hline Economic growth (mean-centered) & $0.01 * * *$ & $(0.00)$ & $0.01 * * *$ & $(0.00)$ & $0.01 * * *$ & $(0.00)$ & $0.01 * * *$ & $(0.00)$ & $0.01 * * *$ & $(0.00)$ & $0.01 * * *$ & $(0.00)$ \\
\hline Constant & $7.09 * * *$ & $(0.01)$ & $7.09 * * *$ & $(0.01)$ & $7.18 * * *$ & $(0.01)$ & $7.18 * * *$ & $(0.01)$ & $7.18 * * *$ & $(0.01)$ & $7.18 * * *$ & $(0.01)$ \\
\hline Number of persons & \multicolumn{2}{|c|}{35,331} & \multicolumn{2}{|c|}{35,331} & \multicolumn{2}{|c|}{35,331} & \multicolumn{2}{|c|}{35,331} & \multicolumn{2}{|c|}{35,331} & \multicolumn{2}{|c|}{35,331} \\
\hline Number of observations & 237 & 619 & 23 & & 23 & & & & 23 & & &, 619 \\
\hline
\end{tabular}

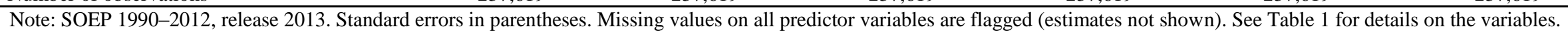
$* * * \mathrm{p}<0.001, * * \mathrm{p}<0.01, * \mathrm{p}<0.05,+\mathrm{p}<0.10$. 